\title{
SEGURANÇA DE DADOS: UMA DIMENSÃO PARA UM AMBIENTE URBANO CRIATIVO E INTELIGENTE
}

DATA SECURITY: A DIMENSION FOR CREATIVE AND INTELLIGENT CITY

\section{Greice Pinto Meireles}

Mestra em Comunicação e Indústria Criativa pela Universidade Federal do Pampa (São Borja/Brasil). E-mail: meireles.greice@gmail.com.

\section{Sara Alves Feitosa}

Doutora em Comunicação e Informação pela

Universidade Federal do Rio Grande do Sul (Porto Alegre/Brasil).

Professora na Universidade Federal do Pampa (São Borja/Brasil).

E-mail: sarafeitosa@unipampa.edu.br. 


\section{RESUMO}

Este artigo parte das dimensões de cidade inteligente do Índice de Cidades Inteligentes de Portugal e propõe a dimensão Segurança de Dados como aspecto a ser trabalhado em cidades criativas e inteligentes. Investiga os elementos que reforçam esta perspectiva como uma sociedade que tem suas interações cada vez mais mediadas pelas Tecnologias da Informação e Comunicação (TICs), além de envolver fatores como a privacidade, ideia de vigilância constante explícita e implícita, dados abertos e destinação deles. Os procedimentos metodológicos adotados foram a pesquisa bibliográfica e a documental. Como resultado, ficou evidenciada a pertinência que esta dimensão Segurança de Dados tem na aplicação dos conceitos e na dinâmica prática de uma cidade inteligente, sendo necessária a existência de uma dimensão específica para tratar as áreas de competência de forma mais direcionada a se pensar uma urbe nestes moldes e por ser uma demanda própria da contemporaneidade social cujas interações se intensificam pelos uso das TICs.

Palavras-chave: Segurança de Dados. Cidade Inteligente. Dimensões de Cidade Inteligente.

\section{ABSTRACT}

This article has as starting point the dimensions of smart city defined in the index of Intelligent Cities of Portugal, as well, it proposes the dimension Data Security as aspect to be treated in creative and intelligent cities. It investigates the elements that strengthen this perspective as a society that has its interactions increasingly mediated by Information and Communication Technologies (ICTS), besides involving factors such as privacy, idea of constant vigilance explicit and implicit, data open and their destination. The methodological procedures adopted were bibliographic and documentary research. As result, the pertinence of this dimension in the application of the concepts and the practical dynamics of an intelligent city was evidenced, being necessary the existence of a specific dimension to treat the areas of competency in a more directed way to think a city in these molds and because it is a demand of the social contemporaneity whose interactions are intensified by the use of ICTs.

Keywords: Data security. Intelligent City. Dimension of Intelligent City. 


\section{INTRODUÇÃO}

Vivencia-se uma transformação dos espaços físicos em que se habitam, onde as Tecnologias de Informação e Comunicação (TICs) tornaram-se tão presentes e integrantes das ações e atividades do homem, o que retoma a importância de observar como este processo está sendo construído, no que tange à sociabilidade humana, no manuseio e interação com os aparatos tecnológicos, como se dá o processo comunicacional dessas relações e o que considerar sobre resguardar estas interações do cidadão-usuário.

O ambiente urbano reflete as transformações das relações humanas e de produção técnica. Ele comporta uma estrutura física e cognitiva, nas quais uma diversidade de atores e instituiç̧ões participantes da sua manutenção - a partir de planejamento e adoção de políticas de desenvolvimento - executam uma série de atividades que constroem a autenticidade e perfil do lugar. Diante disso, surgem estratégias para fomentar este desenvolvimento da cidade, por vezes concebidos em outras realidades, como os conceitos de Cidade Criativa e Cidade Inteligente.

Cidade Criativa propõe o aspecto da inserção da inventividade nos processos urbanos, integração entre entidades que compõem os setores da cidade e valorização da cultura local, ao mobilizar cidadãos a fim de resolver os inúmeros problemas urbanos, podendo até gerar impulso econômico. Já a Cidade Inteligente traz a discussão de como utilizar a tecnologia, o conhecimento e o recurso intelectual para desenvolver os municípios no sentido de torná-los mais sensiveis às necessidades daqueles que os habitam. Esta ganha notoriedade pelas implementações das TICs em estruturas sociais, de governo e principalmente urbanas. Sob essa lógica de aplicação prática, o Índice de Cidades Inteligentes - Portugal (SELADA, 2012) caracteriza cinco dimensões para uma Cidade Inteligente: Governança, Inovação, Sustentabilidade, Inclusão e Conectividade. Dessa forma, entende-se que ambos os conceitos podem ser articulados na medida em que se empenham a oferecer alternativas de melhor convivência e aproveitamento dos recursos tangiveis e intangiveis no tecido urbano, a partir dos elementos de criatividade, conhecimento e inovação, e assim aperfeiçoar a experiência de vida nas urbes.

Este artigo tem por objetivo propor a dimensão Segurança de Dados a ser trabalhada no ambiente urbano criativo e inteligente. Investiga os elementos que reforçam esta perspectiva como uma sociedade que tem suas interações cada vez mais mediadas pelas Tecnologias da Informação e Comunicação (TICs), além de envolver fatores como a privacidade, ideia de vigilância constante visível e invisível, considerar 
a abertura de dados e destinação deles. É resultado de uma investigação propositiva elaborada na dissertação de mestrado da autora e aqui se faz o recorte e aprofunda uma das dimensões propostas.

Na metodologia se usa a pesquisa bibliográfica sobre literatura especializada no conceito de Cidade Inteligente, a fim de criar um quadro lógico de concepções e estabelecer as nuances do conceito. Também se utiliza a pesquisa documental, a partir de fontes mais diversas, como entrevistas com pesquisadores brasileiros, o professor André Lemos (UFBA), professora Patricia Huelsen e professor Marcelo Graglia (PUC/SP), sobre cibercultura e aplicação da inteligência em espaços urbanos. A partir das entrevistas identificaram-se sugestões e questionamentos em torno das dimensões de Cidade Inteligente, assim surgiu a ideia de se debruçar na elaboração de uma proposta de outras dimensões a serem agregadas às de Selada (2012).

No próximo tópico serão abordadas as noções de Cidade Inteligente, bem como suas dimensões. Também será apresentada a análise e motivações para a existência de uma dimensão específica de Segurança de Dados, objeto de interesse do artigo ora apresentado.

\section{CIDADE INTELIGENTE}

O Índice de Cidades Inteligentes - Portugal (SELADA, 2012, p. 09), define Cidades Inteligentes "como génese a utilização de tecnologias de informação e comunicação para promover a competitividade econômica, a sustentabilidade ambiental e a qualidade de vida dos cidadãos". Além disso, o estudo aponta que mais do que servir de forma funcional para as rotinas da cidade, o conceito prevê que as TICs sejam capazes de antecipar problemas e assim, ser possível monitorar, analisar e planejar a cidade para determinadas situações. Selada $(2012$, p. 09) salienta que "o desafio tecnológico das smart cities passa pela integração de tecnologias e pela capacidade de comunicação entre os vários sistemas e redes urbanas", apesar de toda a tecnologia disponivel continua sendo preciso investigar a melhor maneira de aplicação a cada contexto, lidar com interfaces e comunicações entre objetos e indivíduos, visando ser benéfico a estes, sem mencionar o investimento econômico que é necessário dispor, o que não é realidade da maioria das cidades em países em desenvolvimento.

\footnotetext{
${ }^{1} \mathrm{O}$ artigo é um recorte da dissertação $A$ comunicação e o urbano criativo e inteligente: contribuição conceitual aplicada às cidades de pequeno e médio porte, desenvolvida no PPGCIC e que propõe novas dimensões a serem agregadas às já estabelecidas no estudo de Selada (2012), são elas: Segurança de dados, Cultura, Gestão de risco e resiliência, Mobilidade urbana, Gestão otimizada de recursos disponíveis e Comunicação.
} 


\section{Gestãoe \\ Desenvolvimento}

Para Selada (2012) nas Cidades Inteligentes as TICs são facilitadoras e não escopo da proposta, pois são comunidades constituídas de pessoas, consequentemente abrigam conhecimento e criatividade. Logo, para uma Cidade Inteligente "apela-se à colaboração entre os diferentes actores urbanos (municípios, universidades, centros de investigação, empresas, cidadãos, etc.) no âmbito de um modelo de governação em rede" (SELADA, 2012, p. 10). Dessa forma, é evidente como a participação dos cidadãos no processo de concepção de políticas públicas e tomada de decisões sobre a vida citadina é fator que engendra a inteligência coletiva, capaz de agregar valor ao conhecimento adquirido individualmente por cidadãos e podendo até aumentar os níveis práticos e aplicação urbana.

Ao introduzir o assunto, Nicos Komninos (2006) fala sobre cidades e comunidades inteligentes, entendendo-as como um movimento emergente que visa à criação de ambientes que melhorem as habilidades e capacidades cognitivas para aprender e inovar. Para o autor, tais ambientes permitem que "capacidades cognitivas superiores e criatividade sejam construídas coletivamente, a partir de combinações de habilidades cognitivas individuais e sistemas de informação que operam nos espaços físicos, institucionais e digitais das cidades" (KOMNINOS, 2006, p 13, tradução nossa)2. Um dos primeiros pesquisadores a teorizar este movimento, já o pensava no sentido de agregar potencial cognitivo humano e habilidades desenvolvidas por dispositivos técnicos - importante considerar inclusive que as TICs são desenvolvidas por humanos.

\footnotetext{
2 "[...] superior cognitive capabilities and creativity to be collectively constructed from combinations of individual cognitive kills and
} information systems that operate in the physical, institutional, and digital spaces of cities" (KOMNINOS, 2006, p. 13). 
Sobre esta incorporação do aspecto tecnológico à vida das cidades, surgem termos vinculados ao conceito da Cidade Inteligente e enfoques, melhor organizadas na Tabela 1. Vale salientar que os dois primeiros são considerados por Fanaya (2016) com uso mais tradicional e servem de gênese para as Cidades Inteligentes:

Tabela 1 - Expressões vinculadas ao conceito de Cidade Inteligente

\begin{tabular}{|c|c|}
\hline Termo & Definição/Enfoque \\
\hline Cibercidade & $\begin{array}{l}\text { Tem base na vigilância e controle dos sistemas de informação que geram feedback a fim de dar } \\
\text { eficiência a governança. }\end{array}$ \\
\hline Cidades digitais $^{1}$ & Representação e simulação digital das cidades no mundo virtual. \\
\hline Smart & $\begin{array}{l}\text { O foco está no investimento em tecnologias aliadas ao capital humano e social, que } \\
\text { embarcadas nos espaços e equipamentos urbanos, são capazes de gerar inovação, } \\
\text { crescimento econômico e qualidade de vida, além de dar abertura ao governo participativo. } \\
\text { Propõe a incorporação de sistemas de informação e comunicação, com todo o seu potencial } \\
\text { presente e futuro, como agentes ativos nos processos de transformações das relações entre } \\
\text { as pessoas e as cidades. }\end{array}$ \\
\hline Smart community & $\begin{array}{l}\text { É uma comunidade que fez um esforço consciente para usar informações tecnológicas para } \\
\text { transformar a vida e o trabalho dentro de sua região de maneira significativa, fundamental e } \\
\text { incremental. }\end{array}$ \\
\hline Intelligent space & $\begin{array}{l}\text { Refere-se a ambientes físicos nos quais as TICs e os sistemas de sensores desaparecem } \\
\text { à medida que se tornam incorporados aos objetos físicos e ao próprio ambiente em que } \\
\text { vivemos, viajamos e trabalhamos. }\end{array}$ \\
\hline Smarte Intelligent cities & $\begin{array}{l}\text { O foco é no capital humano das cidades, as produções de inovação e de conhecimento } \\
\text { constituídos pela inteligência coletiva em cooperação, a partir do uso de sistemas e } \\
\text { aplicativos coletivos. Possuem condições de gerar novos sistemas simbólicos, ou sistemas de } \\
\text { representação, por meio da dinâmica integrada entre os espaços, as tecnologias e as pessoas. }\end{array}$ \\
\hline Cidade sensiente & $\begin{array}{l}\text { A capacidade que a cidade tem de sentir o que acontece nela, porém não é capaz de saber } \\
\text { conscientemente dos processos. As TICs embarcadas na estrutura física urbana, imbuídas de } \\
\text { coletar conteúdos para lembrar, correlacionar e antecipar situações. }\end{array}$ \\
\hline Cidade cognitiva & $\begin{array}{l}\text { Os ambientes urbanos, por mais que sejam coletivos, geram percepções individuais. Para que } \\
\text { o potencial transforme o futuro habitat urbano em efetividade, é necessário que se comece } \\
\text { com uma abordagem cultural e criativa do design da urbe. É necessário relacionar o espaço a } \\
\text { economia, tecnologia, cultural, política, religião, educação e comportamento. As pessoas são } \\
\text { agentes intrínsecos a essas áreas. }\end{array}$ \\
\hline
\end{tabular}

Fonte: Elaborada pela autora a partir de Komninos (2006); Santaella (2016); Fanaya (2016) 
Entende-se que para Komninos (2006) a característica marcante de cidades e regiões inteligentes é a inovação e o conhecimento, pois aumentam o desempenho na resolução de novos problemas. Constituem-se de sistemas territoriais avançados de inovação, em que os mecanismos institucionais de produção e aplicação de conhecimento são facilitados por espaços digitais e ferramentas online para comunicação, bem como para gerir esses conhecimentos.

Para Fanaya (2016) as Cidades Inteligentes hoje são ambientes cognitivos, pois:

[...] o envolvimento, a consciência, a criatividade, a capacidade de lidar com as incertezas, de olhar a centralidade e a importância da sustentabilidade dependem de se investir em cidadãos bem preparados, conscientes politicamente, alfabetizados digitalmente e capacitados a usar ativamente as tecnologias disponíveis e as que surgirão, a fim de transformar os espaços dinâmicos das cidades em ambientes inteligentes e de aprendizagem (FANAYA, 2016, p. 18).

Nesse sentido, infraestrutura e integração tecnológica são imprescindiveis e permitem a inclusão digital, podem aguçar a curiosidade e despertar interesse de participação, pois para que a cidade seja um ambiente cognitivo é necessário que as pessoas sejam agentes transformadores. Segundo Fanaya (2016), apesar dos seres humanos serem compostos pela materialidade, precisam do outro, do simbólico, da arte, das crenças e da história, pois enquanto seres que aprendem com a experiência, têm as dimensões física e simbólica, que permitem que atribua sentido à tais experiências e a estar no mundo.

Nesta linha, Santaella (2016) observa que a inteligência na cidade apresenta dois aspectos: os visíveis e os invisíveis. Os visíveis podem ser notados claramente, não necessariamente por transformação dos ambientes físicos da cidade em termos de infraestrutura hard, mas a visível alteração do comportamento humano com relação a utilização de aparatos tecnológicos, como por exemplo ser comum vermos pessoas "dedilhando freneticamente" seus smartphones. Os aspectos invisíveis, partindo da ubiquidade dos dispositivos móveis, correspondem à composição de um "ecossistema urbano" dotado de seres actantes - seres que induzem o outro a ação, numa dinâmica de ocorrências. Tal ecossistema também diz respeito às tecnologias embarcadas no ambiente, que se conecta aos dispositivos pessoais gerando uma gama de dados, informações e comunicações em redes conectivas "arquicomplexas". A invisibilidade está na capacidade dos indivíduos serem acessados, sem que se perceba do mesmo modo a captura de dados que projetam um estilo de vida e características destes por quem também está invisível.

Atualmente, os projetos de Cidades Inteligentes em um determinado espaço urbano é palco de experiências desse uso intensivo das TICs, da geração de informações sensiveis ao ambiente através da conexão entre as coisas, de administração urbana com base em ação social dirigida por dados abertos, a 
fim de aprimorar e contribuir, significativamente, seja na vida ou trabalho das pessoas em certa região. É nesse aspecto de experiência que se remete a ideia de laboratório vivo que as cidades possuem, salientada pelos estudiosos da Escola de Chicago ${ }^{3}$, que se pensa aqui a relação das TICs e segurança de dados. Assim, nem toda a cidade digital seria inteligente, no entanto a Cidade Inteligente deve ter certos atributos digitais.

Lemos e Mont'alverne (2015) colocam ações em três áreas como fundamentais nas Cidades Inteligentes: infraestrutura, gestão urbana e dados abertos. A forma de gestão urbana é parte estruturante e agregadora das iniciativas que favorecem uma Cidade Inteligente. Lemos e Mont'alverne (2015) identificam três modelos de organização dos projetos de Cidades Inteligentes:

1) Made from scratsh ou organização feita do zero são projetos em que se constroem as cidades planejadas, geralmente com fins de sustentabilidade, um exemplo é Masdar, em Abu Dhabi, nos Emirados Árabes. Tais projetos carregam identidade e historicidade própria de um ambiente social que já existe, do seu povo.

2) Organização Centralizada são projetos orientados a partir das instituições governamentais, a administração pública municipal, que promovem ações de práticas inteligentes na cidade, é o caso de Porto Alegre, com abertura de dados em linguagem acessível para os cidadãos, e do Rio de Janeiro, pelo sistema de monitoramento de clima, a fim de evitar desastres naturais, bem como de segurança e de trânsito.

3) Organização Descentralizada são projetos implementados com base em ações da administração pública e empresas privadas, como acontece em Búzios com o smart grid, sistema de gestão da energia elétrica.

Para os pesquisadores os três modelos têm falhas a serem superadas, sendo a centralizada observada como mais promissora, mas que também precisaria da abertura, não podendo ser instituída de cima para baixo, ou seja, que na decisão de construir uma Cidade Inteligente não prevaleça os interesses de determinados setores da sociedade, devendo ser uma construção coletiva, já que ela se sustenta do capital intelectual humano que a habita. Nestes projetos, cada setor da sociedade colabora com

\footnotetext{
${ }^{3}$ Durante a década de 1920, na Universidade de Chicago, surgiu uma tendência intelectual cuja linha de pensamento se voltava ao debate sobre o cotidiano da cidade e os problemas da convivência urbana provenientes das novas dinâmicas de aumento populacional, multiculturalismo, estruturação econômica, social e política. A Escola de Chicago, como ficou conhecida, era orientada por uma sociologia das relações (ou uma sociologia urbana), em que o interesse dos pesquisadores era "pelo particular e pelas pequenas ocorrências da vida cotidiana - tendo sido especialmente afetados e tematizados pela própria cidade onde viviam" (FRANÇA; SIMÕES, 2016, p. 84).
} 
uma parcela de esforço intelectual, sendo a intervenção do Estado necessária para equilibrar de forma isonômica e equitativa as contribuiç̧ões e interesses.

Neste aspecto, Santaella (2016) comenta que a par da governabilidade, existem inúmeros ativistas, hackers e empreendedores civis que, através das lacunas, delineiam diversos modos e interfaces para que os sujeitos possam sentir e interagir com as cidades de maneira completamente inusitada. 0 que permite que ao invés de "monopólios proprietários, eles constroem redes colaborativas para diferentes finalidades da vida urbana [...] [iniciativas que] podem parecer de pequena escala, mas têm o potencial de viralizar nas redes" (SANTAELLA, 2016, p. 34).

Em sintese, esses projetos agregam, portanto, três elementos das TICs: Internet das Coisas (objetos com capacidades comunicacionais avançadas de conexão entre si), Big Data (processamento e análise de grande volume de conteúdo e informação) e Governança Algorítmica (gestão e planejamento com base em ações construídas por algoritmos aplicados à vida urbana que geram dados, informações e indicadores, a partir dos quais sistemas e dispositivos eletrônicos autômatos são incumbidos de decisões). 0 objetivo é criar condições de qualidade de vida, ambientes mais sustentáveis, além de fomentar o potencial intelectual demográfico presente naquela localidade, bem como a inovação partindo da economia criativa e gestão, utilizando as TICs como instrumentos.

O movimento no âmbito das cidades quanto ao desenvolvimento das TICs atuais, que passam a ser vistas como a chave da engrenagem de diversos movimentos em prol do bem-estar social, permitem ações que refletem diretamente no cotidiano das cidades e, sem até serem notadas, vão se tornando importantes e grandes facilitadoras, como a proliferação de dados e cruzamento deles, que podem identificar problemas e prospectar estratégias mais eficientes. Segundo o pesquisador norte-americano Anthony Townsend (2013), especialista em aplicações de tecnologias nas cidades e instituições públicas, Cidades Inteligentes podem ser entendidas como:

[...] lugares onde a tecnologia de informação é manejada para abordar antigos e novos problemas. No passado, construção e infraestrutura desviavam do fluxo de pessoas e bens, de maneira rigidamente predeterminada. Mas cidades inteligentes podem se adaptar em tempo real, a partir da leitura de vastos conjuntos de sensores, fornecendo os dados em software que pode dar uma visão ampla da cidade e favorecer para tomar medidas pontuais (TOWNSEND, 2013, p. 58-59, tradução nossa)4.

\footnotetext{
4 "Smart cities are places where informations technology is wielded address problems old and new. In the past, buildings and infrastructures hunted the flow of people and goods in rigid, predetermined ways. But smart cities can adapt on fly, by pulling readings from vast arrays of sensors, feeding that data into software that can see the big picture, and taking action" (TOWNSEND, 2013, p. 58-59).
} 
A ideia é que as tecnologias de informação emergentes funcionem como o sistema nervoso da cidade e, no mínimo conflito ou desgaste, possa gerar alerta. A noção de inteligência das cidades agrega as ferramentas da cidade digital mais o capital humano e social, produtores de conhecimento, informação e criatividade, os ativos essenciais.

Tanto Townsend (2013) quanto Lemos (2015) mencionam a conectividade das coisas/objetos Internet das coisas - e o tratamento de um volume de dados em rede - Big Data - como os principais instrumentos utilizados na inteligência das cidades. As iniciativas focam o uso das TICs e a conexão entre todas as coisas, assim, além das pessoas estarem conectadas, os objetos também estão, para aprimorar e contribuir, significativamente, seja na vida ou trabalho das pessoas em certa região. Santaella avalia que os big datas são ferramentas "imanentes para suportar a vida urbana" (SANTAELLA, 2016, p. 33), que oportunizam repensar uma "governabilidade a partir de um modelo mais aberto, transparente, democrático e responsivo" (SANTAELLA, 2016, p. 33-34), mas que há ambivalências, das quais o ponto de contraste está na vigilância e controle da privacidade, no "rastreamento de nossas experiências vividas" (SANTAELLA, 2016, p. 35), tudo o que se consome, os interesses e hábitos geram dados documentados em relatórios, porém não se tem a dimensão de quem terá acesso a eles.

André Lemos lembra que assim como existem Cidades Inteligentes, também temos smarts citizens (cidadãos inteligentes) e que as pessoas da mesma forma passam a produzir e gerar informação (2013). Neste sentido, Townsend (2013) expõe que estamos vivendo o nascimento de um movimento civil, em que os smartphones exercem papel importante quando utilizados para reivindicações, de maneira que os movimentos partem de baixo para cima, ou seja, cidadãos mobilizados pressionam os espaços de poder constituídos a responder sobre suas necessidades, bem como iniciativas próprias sem depender dos órgãos institucionais. De acordo com o autor, usuários de smartphone criam aplicativos de geolocalização com a intenção de encontrar coisas, pessoas, lugares ou simplesmente realizarem ações para facilitar suas vidas. Nas próprias casas, as pessoas, ainda que distantes, podem programar seus utensillios domésticos para executar funções. Estando no trabalho, poderia acionar a roupa para ser lavada, a geladeira pode fornecer informação dos alimentos que estão falando, dentre outras possibilidades.

Neste sentido, a abertura dos dados é pensar o próprio cidadão, pois ao abri-los permite que o usuário tenha conhecimento tanto do que se expressa neles como da maneira como se constroem e sua contribuiçã̃o a partir do que produz de dados compõe esses conteúdos e se fazem úteis a outros. A ideia de cidadania está vinculada ao cenário social, no que se refere ao saber, ler, interpretar, escrever e estar a par do entendimento sobre as leis que regem o meio social que estão inseridos. Nesta dimensão, se articula a noção de um "cidadão sensor", que passa a ser convocado para produzir dados que auxiliam nas melhorias do espaço compartilhado. 
Fanaya (2016) salienta a importância dos dispositivos pessoais daqueles que interagem no ambiente urbano, para que possam estar conectados e expandir suas capacidades através das informações incorporadas aos espaços e equipamentos da cidade. "Ou seja, é necessário possibilitar que habitantes e visitantes recebam, compartilhem, remixem, co-criem e deem e recebam feedback de informações sobre as cidades" (FANAYA, 2016, p. 19), através do processo de interação, constitui-se a dimensão da comunicação e de construção dos sentidos para estes ambientes cognitivos.

Vale salientar, de acordo com Selada (2012), que mesmo não havendo uma definição única do conceito, o que existe é uma multiplicidade de projetos e experiências com objetivos, motivações, ações, parcerias e financiamentos diversos, os quais ainda apresentam diferentes estágios de maturidade. As TICS, dados das interações, informação analítica gerada a partir destes, servem como auxílio para os tomadores de decisões. Permitem racionalizar e embasar melhor as decisões, perante as necessidades e riscos do processo avaliado. Neste limiar, este conceito traz a oportunidade de empenhar esforços de áreas diversas em torno de um denominador comum que é a própria cidade.

\subsection{DIMENSÕES DE CIDADE INTELIGENTE}

A Cidade Inteligente avança em direção de uma robusta integração de dimensões da inteligência humana e coletiva junto da técnica e artificial, disponíveis em determinado espaço geográfico com delimitação demográfica, que se nomeia de cidade. O ambiente cognitivo da cidade com base na inteligência é composto por humanos e não humanos trabalhando em cooperação. Estes são seus elementos básicos. Partindo-se disso, os projetos de Cidades Inteligentes precisam se organizar enquanto objetivos e áreas que precisam atuar para melhor organização e sucesso de suas investidas.

Pode-se inferir que, sob esta lógica, o Índice de Cidades Inteligentes - Portugal (SELADA, 2012) criou uma metodologia para o desenvolvimento das cidades portuguesas. 0 interessante do estudo é que abarca cidades de quaisquer tamanhos, sendo muitas iniciativas identificadas em cidades de pequeno e médio porte. Assim, Selada afirma que:

[...] objetivo é não só posicionar estrategicamente as cidades portuguesas, mas também produzir recomendações para a melhoria do desempenho dos territórios. Pretende-se ainda estimular a cooperação intermunicipal através do lançamento de projetos conjuntos numa lógica de rede de cidades. (SELADA, p. 07).

Para a melhoria do desempenho dos territórios, entende-se que o Índice propõe, a partir da atração de pessoas talentosas, visitantes e investidores que unam a inovação, a qualificação do ambiente e a 
inclusão social e cultural, num contexto de governança aberta e de conectividade, inclusive com a economia global, visando a qualidade de vida dos cidadãos.

O Índice de Cidades Inteligentes - Portugal (SELADA, 2012) caracteriza cinco dimensões para uma Cidade Inteligente: Governança5̆ Inovação, Sustentabilidade, Inclusão e Conectividade.

A Governança diz respeito ao ato de governar incluindo os processos de simplificação e modernização administrativa, a disponibilidade de serviços públicos digitais e as formas de participação pública, bem como transparência quanto às ações de gestão e criação de políticas urbanas estratégicas para o desenvolvimento.

A Inovação corresponde ao investimento municipal em Pesquisa, Inovação e Desenvolvimento, ao incentivo do empreendedorismo, de empregos nos setores associados às TICs, à existência de infraestruturas e à cooperação tecnológica entre instituições; bem como alternativas de economia verde, no sentido de formular tecnologias de melhora aos impactos ambientais e aproveitamento dos recursos naturais, além do fomento à economia criativa e economia solidária. Inovação é cada vez mais considerada como um processo de colaboração e evolução ocorrendo dentro de ambientes que aumentam a geração de ideias e descobertas, além da seleção destas que sejam as inovações mais plausíveis e aplicáveis na realidade.

Sustentabilidade se refere em pensar alternativas, práticas e análise de diversos fatores críticos de otimização e melhor utilização dos recursos naturais, da biodiversidade e ecologia, assim como na purificação do ar e redução de emissões, ao evitar o desperdício da água, redução de resíduos e energia e quanto ao melhor planejamento de construção de edifícios e vias de mobilidade para diminuição de impactos no meio ambiente.

A Inclusão está nos seguintes fatores: ações de coesão social, respeito e incentivo à diversidade social e cultural, engajamento pelo empreendedorismo e inovação social e de inclusão digital. Neste âmbito, além do empenho para minimizar a exclusão social, também corresponde ao livre acesso aos bens e serviços culturais e criativos. A cultura ${ }^{6}$ é percebida como a quarta coluna do desenvolvimento sustentável, junto das dimensões econômica, social e ambiental.

\footnotetext{
5 Termo usado em Portugal é Governação, mas neste trabalho optamos usar Governança, por ser correspondente em mesmo grau e sentido no dicionário brasileiro e ser mais usado. Etimologicamente Governação é entendido como ato de governar. Ambas as expressões referem-se à forma de governar baseada no equilíbrio entre o Estado, a sociedade civil e o mercado, ao nível local, nacional e internacional.

${ }^{6} \mathrm{Na}$ dissertação "A comunicação e o urbano criativo e inteligente: contribuição conceitual aplicada às cidades de pequeno e médio porte" (MEIRELES, 2018) é proposto Cultura como uma dimensão exclusiva, mas este aspecto não será tratado no presente artigo.
} 
A Conectividade promove indicadores relativos às Tecnologias de Informação e Comunicação (TICs) ou redes digitais e a própria constituição de redes territoriais.

\section{METODOLOGIA}

Para a realização deste trabalho, utiliza-se a pesquisa bibliográfica, que conforme Ida Stumpf (2010, p. 51) consiste em "um conjunto de procedimentos que visa identificar informações bibliográficas, selecionar documentos pertinentes ao tema estudado". É uma pesquisa que se inicia desde a delimitação do tema e definição da problemática, inclusive dá suporte para a formulação do problema, na medida em que o pesquisador - a partir da produção científica mapeada - consegue identificar lacunas, nas quais sua pesquisa pode se inserir e, então, fazer contribuições. A pesquisa bibliográfica compreende "desde a identificação, localização e obtenção da bibliografia pertinente sobre o assunto, até a apresentação de um texto sistematizado" (STUMPF, 2010, p. 51). Este tipo de texto contém definições sobre produções existentes, que são referências no campo estudado, a fim de evidenciar o entendimento de autores e relacionar suas discussões, que podem se complementar ou se contrastar. Além disso, é possível associar as opiniões auxiliares ao assunto, as quais permitem corroborar o conhecimento de dimensões mais completas e trazer outras perspectivas, além das abordagens de viés crítico para que a proposta ganhe um adensamento teórico. No entanto, considera-se que mesmo se tais aspectos forem investigados, "é impossivel num só trabalho abordá-lo [tema] sob todos os ângulos" (STUMPF, 2010, p. 55).

A fase inicial da referida pesquisa partiu da localização do aporte teórico dos conceitos centrais abordados, através de bibliografias especializadas e autores referência. Organizou-se, então, uma sequência lógica de ideias para formar o quadro referencial teórico e conceitual. Assim, as referências utilizadas para relacionar as concepções de Cidade Inteligente foram Catarina Selada (2012), organizadora do Índice de Cidades Inteligentes - Portugal, em Anthony Townsend (2013), André Lemos (2013; 2016; 2017), André Lemos e Adelino Mont'alverne (2015), Lucia Santaella (2016), Nicos Konminos e Elena Sefertzi (2009) e Patrícia Fanaya (2016).

A pesquisa documental segue os mesmos caminhos da pesquisa bibliográfica, por vezes é difícil distingui-las, e o mecanismo para identificá-las está na natureza das fontes (GIL, 2006). Enquanto a pesquisa bibliográfica se fundamenta em fontes elaboradas e publicadas primeiramente em livros e artigos científicos localizados em bibliotecas físicas e digitais, por outro lado, a pesquisa documental serve-se de fontes mais diversas, que se localiza em veículos dispersos e sem tratamento analítico necessariamente, assim pode ser: relatórios, documentos oficiais, índices estatísticos, imagens, material audiovisual, notícias de jornais, revistas, sites, entrevistas não publicadas, etc. Neste sentido, fundamentalmente, este trabalho 
faz uso de dados de relatórios como a Pesquisa sobre o uso das Tecnologias de Informação e Comunicação nos domicílios brasileiros - TIC Domicílios 2016, do Comitê de Gestão da Internet (CGI); do Índice de Cidades Inteligentes - Portugal7 e de entrevistas realizadas em audiovisual, pela autora, para compor a websérie São Borja Conectada ${ }^{8}$ (MEIRELES, 2017), com pesquisadores como André Lemos, da Universidade Federal da Bahia (UFBA), Patricia Huelsen e Marcelo Graglia, ambos da Pontifícia Universidade Católica de São Paulo (PUC/SP). O objetivo das entrevistas era trazer um olhar especialista sobre os temas abordados na websérie. A São Borja Conectada é um produto para os componentes Pesquisa, Desenvolvimento \& Inovação - Planejamento e Pesquisa, Desenvolvimento e Inovação - Execução (PD\&I) ${ }^{9}$, partes da estrutura curricular do Programa de Pós-graduação em Comunicação e Indústria Criativa (PPGCIC), da Universidade Federal do Pampa (UNIPAMPA).

A entrevista com André Lemos foi através de uma conversa em vídeo pelo Skype, no dia 06/09/2017; a entrevista com os pesquisadores Patricia Huelsen e Marcelo Graglia aconteceu em conjunto no dia 27/11/2017, em uma ligação por vídeo no aplicativo FaceTime, ambas utilizaram softwares de gravação. As primeiras ideias para aprofundar a discussão nas dimensões de uma cidade inteligente surgiram a partir das falas dos entrevistados.

\section{RESULTADOS E ANÁLISE: A DIMENSÃO SEGURANÇA DE DADOS}

Com ascensão das TICs, presencia-se um novo entrosamento no espaço urbano, onde, a princípio, os dispositivos atuam de modo a facilitar o convívio entre cidadãos e as relações estabelecidas com a cidade, no entanto ambivalências se manifestam. Considerando o espaço público na urbe como um local cuja força vital está além das trocas convencionais de convívio social, mas também o vendo como difusor de conhecimento e informações, é necessário observar que estas informações precisam ser resguardadas dentro das interações em que foram concebidas e consentidas entre seus interagentes, o que evidencia a necessidade de uma dimensão específica para tratar este elemento chave nas estratégias para a cidade com base na inteligência, ou seja, a segurança de dados.

\footnotetext{
${ }^{7}$ http://www.inteli.pt/pt/go/indice-cidades-inteligentes-2020

${ }^{8}$ A websérie São Borja Conectada propõe provocar os habitantes da cidade de São Borja, localizada na fronteira oeste do Rio Grande do Sul, sobre o ambiente urbano contemporâneo, que abriga as relações humanas entre si e com a tecnologia, sob a perspectiva dos conceitos de Cidade Criativa e Cidade Inteligente, bem como suas dimensões: Governança, Inovação, Sustentabilidade, Inclusão e Conectividade (SELADA, 2012). Saiba mais: www.facebook.com/SBConectada

9 Saiba mais sobre os Projetos de PD\&I do PPGCIC: http://cursos.unipampa.edu.br/cursos/ppgcic/projetos-2017-2018/
} 
Para toda e qualquer cidade já se presume existirem órgãos governamentais que cuidam da segurança pública. Em uma Cidade Inteligente precisa se tencionar e preparar mecanismos para proteção dos dados de seus cidadãos, além de estabelecer um regime de transparência sobre o uso deles. Esta dimensão envolve a discussão sobre a vigilância e privacidade, controle, desconhecimento do funcionamento e grau de invasão, inclusão, inovação, governança e conectividade. Neste sentido, dialoga com as demais dimensões.

Santaella (2013) ao discutir a privacidade, primeiro retoma a concepção inicial de Aristóteles sobre o que é público e privado, que se estabeleceu, por alto, como público sendo de ordem do Estado e privado da sociedade civil. Santaella (2013, p. 72) entende que "privacidade significa a proteção do eu em relação ao Estado, às organizações e aos outros indivíduos", isto é, implica uma dinâmica individual, algo particular do sujeito, correspondendo exatamente à apropriação que se fez dos dispositivos móveis pelo indivíduo, nos quais suas interações - os dados que gera, os conteúdos que produz e consome, as comunicações que emite - só dizem respeito a ele, a princípio, se não estiver infringindo leis. É um espaço de controle individual.

A autora ressalta que "os problemas sociais relativos à privacidade são muito mais complexos do que a simples invasão da privacidade individual" (SANTAELLA, 2013, p. 76), porque o conceito de privacidade tem muitas conotações teóricas, abordagens legais e sem aderência real na vontade facultativa dos sujeitos. Neste limiar, a proteção da privacidade não necessariamente resolve o problema da vigilância e nem garante a segurança de dados.

De acordo com Santaella (2011), há três regimes de vigilância: o panóptico, o escópico e o ubíquo ou por rastreamento. O primeiro, derivado dos estudos de Michel Foucault e Jeremy Bentham, a panóptica, refere-se à vigilância disciplinar que é exercida em ambientes bastante circunscritos, implantada para administração e contenção de seus membros, como prisões, hospitais, escolas, fábricas e empresas, dentre outros. O regime escópico corresponde à proliferação da distribuição, para diversos fins, de gravação de câmeras e visualização de imagens, em locais estratégicos tanto internos como externos. Já o ubíquo ou por rastreamento, próprio da era digital, é feito por máquinas invisíveis e sensitivas, cujos padrões complexos de leitura de dados e infiltrações no cotidiano dos sujeitos, tornam-se cada vez mais sutis. É uma vigilância invisível, também anônima e obscura, sem fins e destino claros.

Cabe decifrar quem pode exercer tal vigilância e controle, principalmente a partir do que pode ser considerado uso sombrio das TICs através do regime mais enigmático da vigilância - a ubíqua - assim pode acontecer entre os próprios indivíduos; entre instituições que compõem o Estado (inclusive órgãos policiais e militares) e indivíduos ou empresas; entre empresas e indivíduos ou Estado; empresas ou Estado a grupos civis organizados. Obviamente, a posse da vigilância é vantagem daqueles aptos e que 
dominam linguagens, códigos e infraestrutura de redes para instaurá-la.

Dessa forma, a privacidade não se resume à permissão para que os movimentos dos cidadãos sejam monitorados em prol da segurança pública e estes entenderem que se nada têm a esconder, permitem "vasculharem" suas vidas. O impasse, então, não é somente pelo acompanhamento da rotina dos sujeitos através de câmeras de captação de imagens, satélites, dispositivos móveis, gadgets vestiveis, chips de identificação, cartões de crédito, de varejo e de transporte, aplicativos de entretenimento, sites de redes sociais, escaneamento biométrico, vírus com mecanismos que danificam e furtam dados, muitos equipados também com tecnologias de geolocalização, adiciona-se o componente mais híbrido, ubíquo e invisivel de cada um desses aparatos.

Atualmente, acumulam-se bases de dados com informações massivas sobre o perfil dos usuários, no qual há registros do histórico de saúde, das finanças, de intelectualidade, de consumo, de lazeres, de deslocamentos e de relações com demais indivíduos, sem que tenha ciência de quais e quantas informações foram reunidas e a quem ficam disponíveis. Acrescenta-se também o nivel matemáticoracional eficaz das tecnologias de Inteligência Artificial que organizarão e interpretarão os conteúdos, é provável que saibam sobre os indivíduos mais do que eles próprios e, inclusive, além do que serão capazes de imaginar.

Se já existe um mercado deste segmento atuando nas interações particulares atuais, que dirá em uma cidade estruturada para funcionar eficientemente, sem imprevistos repentinos e nem tumultos, que necessita ser alimentada por dados preditivos. Isto é, os dados são um elemento central e merecem um cuidado especial. Logo, culminam questionamentos: quais dados carecem de ser obtidos sobre a cidade e os habitantes? De que maneiras devem ser processados, disponibilizados, conservados e descartados? Admitir o compartilhamento e reutilização pela comunidade? Em quais âmbitos de gestão: público ou privado? Na verdade, são inquietações provenientes já do contexto contemporâneo, hoje ainda não se tem a completa noção sobre a coleta, rastreamento e destino das interações que se realiza nas redes, o que potencializa a preocupação ao se pensar quanto as da urbe.

Serve-se a discussão, o contexto em que dados dos cidadãos são acessados e utilizados sem clareza de como, por quem e para quê. Isto ganha repercussão após o episódio da participação da empresa Cambridge Analytica (CA) na eleição presidencial nos Estados Unidos, em 2016. A CA é uma empresa privada que trabalha com data-driven marketing ${ }^{10}$, combina mineração e análise de dados com comunicação estratégica para fins comerciais e políticos, basicamente utiliza técnicas de análise de personalidade para

${ }_{10}$ Marketing de dados direcionados. 
elaborar propagandas direcionadas a determinados perfis com a intenção de estimular comportamento e atitudes favoráveis ou não sobre certo assunto de interesse do contratante do serviço. A empresa apoiase em behavioral sciences ${ }^{11}$ para gerar o perfil psicográfico das pessoas acessadas. Importante ressaltar que a empresa sinalizou a intenção de atuar no Brasil e refletir que provavelmente não é a única do segmento no mundo.

Estima-se a coleta de informações de 50 milhões de norte-americanos. Iniciou-se por meio de uma aplicação incorporada ao Facebook, chamada thisisyourdigitallife, cujo fim era na utilização de uma pesquisa acadêmica ligada à Universidade de Cambridge. O sistema incluía questionários sobre orientação política, QI, religião e temas de interesse, também pedia consentimento para acesso às demais informações cadastradas no perfil. Nisso, 320 mil pessoas permitiram o acesso e a aplicação foi pegando os dados também da rede de amigos delas, numa contínua derivação de informações até chegar a um número maior.

As fases do trabalho consistem em coletar dados a partir de um banco - no caso norte-americano, foram os do Facebook -, depois usar o big data como método para tratá-los, cruzá-los e transformar em informação útil sobre a personalidade dos sujeitos e, por fim, criar e disseminar propagandas adequadas a cada perfil. O cruzamento de dados não é inédito, a técnica era aplicada já na coleta de dados dos cookies de navegadores de sites, a questão é que foi potencializada e aprimorada para resultados ainda mais sombrios, com a criação de notícias e provas inventadas pela adulteração de conteúdos, além da intenção de persuadir.

O caso ilustra o quanto os cidadãos estão reféns das corporações comerciais, das detentoras de inovações tecnológicas, dos poderes instituídos, sendo urgente uma educação digital nesse sentido e uma inteligência que pense a segurança de dados, para que uma Cidade Inteligente seja nutrida de conteúdos derivados dos dispositivos de seus habitantes, mas com um regime de transparência sobre a utilização. Isso só ganhará corpo se a sociedade civil se organizar para o debate e inserção na agenda de políticas de proteção.

O relatório anual do projeto "Quem defende seus dados?" (QDSD), da InternetLab"12, visa promover

\footnotetext{
${ }^{11}$ A behavioral sciences atua na identificação de cinco perfis: 1) abertura: receptividade da pessoa a novas experiências; 2) nivel de consciência: cuidado do indivíduo com organização e eficiência; 3) extroversão: grau de sociabilidade e tendência a encarar positivamente os acontecimentos; 4) amabilidade: nível de empatia, sensibilidade e cooperação com os outros; e 3) instabilidade emocional ou neurose: intensidade emocional ao obter informações e condição de reação (FLORES, 2017).

12 Organização independente, sem fins lucrativos, promove pesquisa interdisciplinar, debate acadêmico e a produção de conhecimento nas áreas de direito e tecnologia sobre a Internet. Atua como meio de articulação entre acadêmicos e representantes dos setores público, privado e da sociedade civil.
} 
a transparência e a adoção de práticas apropriadas no tópico de privacidade e proteção de dados em específico pelas empresas provedoras de acesso à Internet atuantes no Brasil e também divulga resultados das pesquisas com fins de conscientizar os brasileiros.

Os parâmetros de avaliação, se a empresa fornece informações ou referências legais claras sobre coleta de dados, são: 1) quais dados são coletados e em que situações a coleta ocorre; 2) os fins para os quais são utilizados e como se dá a utilização; 3) por quanto tempo, onde são armazenados e quando/ se são apagados; 4) quais as práticas de segurança observadas na guarda de dados, se há política de anonimização de dados e quem teria acesso aos dados, observando também o disposto no art. 16 do Decreto no 8.771/2016; 5) se há informações sobre as circunstâncias em que isso aconteceria ou/e a necessidade de autorização do cliente para tal; e 5) se há facilidade de acesso a tais informações a partir do site da empresa.

Figura 1 - Resultados da pesquisa “QDSD?”, 2018

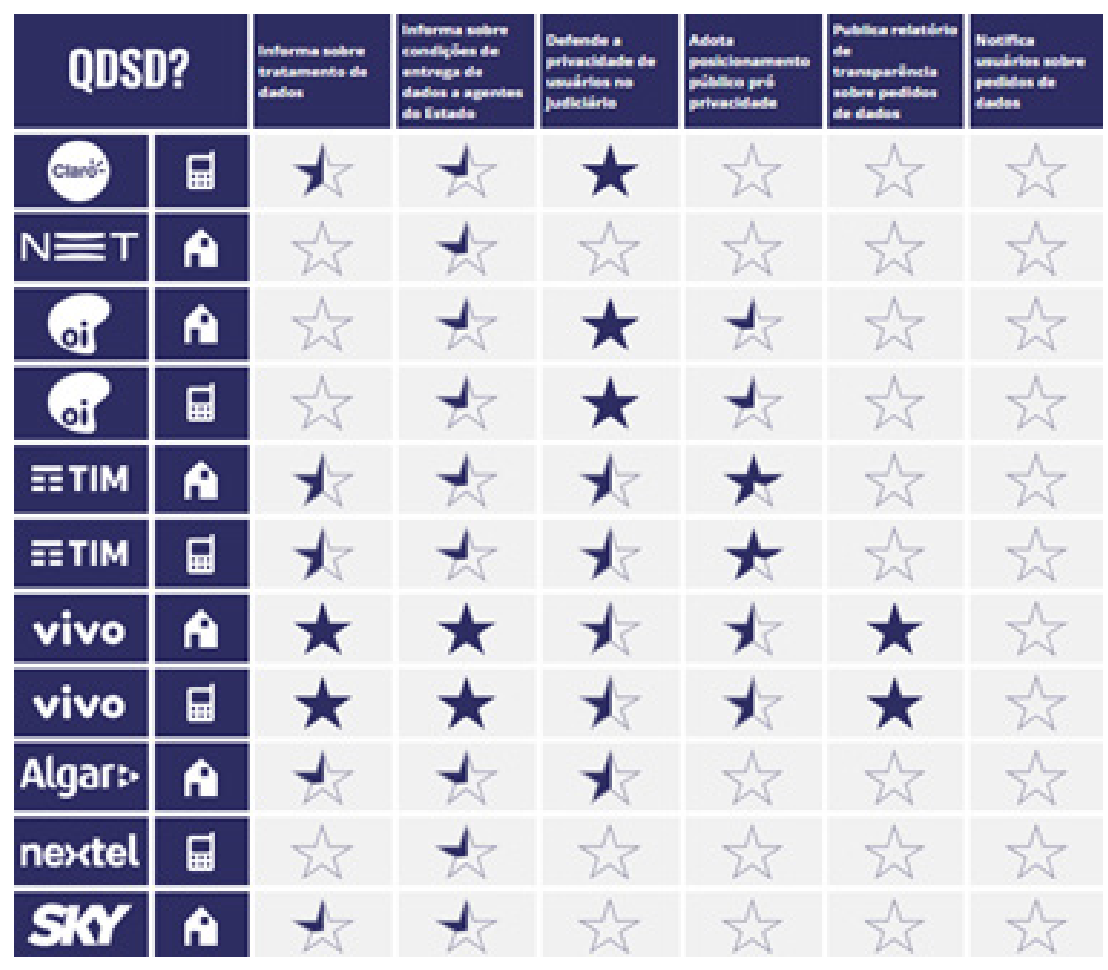

Fonte: InternetLab (2018) 
A maioria atende de dois a quatros dos parâmetros, a pesquisa ajuda ter uma noção sobre o contexto brasileiro quanto à segurança dos dados. Se, por um lado, em provedoras de acesso à internet de banda larga fixa e de internet móvel, nas quais os serviços são pagos pelos cidadãos, nota-se lacunas quanto à transparência sobre uso dos dados, por outro, observa-se um empenho maior destas em corresponder às demandas do Estado e de proteção jurídica das suas atividades. Vale ressaltar que nenhuma das operadoras analisadas pela pesquisa QDSD têm uma política de notificação sobre pedidos de dados aos usuários.

À vista disso, entende-se que a segurança é um campo fértil para debate e pesquisas, defende-se uma dimensão específica porque tem a ver com a proteção da base que orientará a tomada de decisões e eficácia das ações na cidade, dessa forma, precisam ser fontes confiáveis, sem interferência persuasiva e de risco de vazamento deste para outros fins. Sendo assim, está articulada às dimensões Governança, Inovação, Conectividade e Inclusão.

No que tange à governança, por mais que os números do Comitê Gestor da Internet (CGI) apontem aumento de uso de smartphones e acesso a redes $3 G$ e 4G, é pouco provável que as pessoas utilizem seus pacotes de dados para interagir sobre questões públicas, a não ser que estejam incomodadas ou sofrendo danos. Sobre este fato, a própria pesquisa indica resultados quanto às atividades realizadas na internet, sendo mencionado o envio de mensagens instantâneas (89\%) e uso de redes sociais (78\%), mas $61 \%$ dos usuários (equivalente a 57 milhões) utilizam o instrumento do governo eletrônico para consultas de serviços ou informações tais como educação pública, impostos e taxas governamentais e documentos pessoais. O relatório (2016, p. 155) avalia que a faixa utilizadora de "[...] serviços de transação pela Internet e ferramentas de participação ainda são pouco ofertados pelos órgãos públicos, como consultas públicas e enquetes on-line", evidenciando que a faixa etária que mais utiliza é de 16 anos, mas ainda assim é pequena a porção dos que entram em contato com o governo pelos serviços disponibilizados.

Contudo, segundo o CGl, o perfil do usuário do governo eletrônico aumenta conforme a renda familiar, ou seja, os de renda mais alta tendo mais acesso que os de renda mais baixa. $O$ estudo atribui as condições de acesso das classes $C$ e $D$, que dificulta a experiência do usuário com conexões de $3 G$ e 4G, refletindo na inclusão. Dentre os motivos pelos quais os usuários têm resistência a usar mais o governo eletrônico estão "a percepção de que o contato com o governo pela Internet é complicado (49\%) e pela preocupação com proteção e segurança dos dados (47\%)" (CGI, 2016, p 153). Apesar disso, o uso do governo eletrônico está aumentando, a tendência é fomentar mais este acesso e para isso diminuir a desconfiança da população quanto à segurança e privacidade. 0 que já evidencia a questão da inclusão sobre o acesso ser maior em classes mais altas, inferindo-se ainda que a conectividade enquanto infraestrutura das redes está melhor distribuída àquela parcela residente em áreas bem localizadas. 
A partir da democratização dos meios de acesso às redes, há a inclusão aos benefícios que as TICs fornecem para a sociedade, também no sentido de que é preciso dar ciência dos sujeitos sobre a instauração deste regime para que venham participar da ampla discussão sobre o futuro desses parâmetros dentro da vida coletiva. Sendo que é um desafio lidar com a segurança de dados até para peritos engenheiros de sistemas, mais complicado é àqueles que estão tendo iniciação às plataformas e não dispõem de completa noção do quão as TICs estão infiltradas e assim comprometem toda sua rede, pois podem ser mais vulneráveis.

A relação com a Inovação, a dimensão da Segurança dos Dados, aqui proposta, está sobre as ferramentas que permitirão tanto a vigilância como a resistência a ela, incentivar a abertura de dados para os cidadãos a fim de despertar o ativismo contra parâmetros de invisibilidade e desconhecimento das ferramentas utilizadas para fins obscuros. É necessário cuidado com as parcerias tecnológicas firmadas, sejam privadas ou públicas, para resguardar direitos de transparência aos citadinos, bem como ter atenção com as mudanças de protocolos, novos produtos e serviços disponibilizados, assim como acompanhar o progresso da tecnologia para cada vez mais proteger os dados dos cidadãos.

Estabelece-se também um vínculo com a Conectividade, por ser pela conexão o caminho de acesso às redes. A conexão também se dá pelos conhecimentos que são construídos para tal resistência, inteligência em como montar a infraestrutura de redes com fins de já proteger os dados, fomentar iniciativas e conectá-las em prol da tenacidade das discussões em torno da segurança de rede.

Apontar tais questões não se trata de demonizar as tecnologias que interagem com o espaço urbano, pois este já está permeado pela presença do digital ubíquo da cultura contemporânea. O que se discute são quais tipos de tecnologia se quer, considerando a relação de construção com a cidade que se quer. Se tais projetos de cidade forem focados no uso de aparatos tecnológicos de grandes empresas do ramo ou de consultoria, caminha-se e abre-se uma brecha para o controle dos cidadãos e aderência da privatização dos espaços públicos.

Dessa forma, o movimento deve ser em torno da tecnologia desenvolvida desde a base com foco na proteção dos usuários e servindo à cidade para otimizar recursos e proporcionar espaço democrático, não o inverso, a cidade servindo à tecnologia como simples laboratório de aplicações, pois isso caracterizaria a Cidade Inteligente como mera experimentação tecnológica, com pouca ou nenhuma transparência no gerenciamento e seguindo a ordem comercial.

Contudo, não é este o foco debatido aqui, mas sim o de fugir desta lógica, pois a proposta é de uma inteligência derivada dos cidadãos, seja com produtos tecnológicos de high ou de low tech para a cidade, pelo incentivo de uso de softwares e hardwares abertos, que proporcionam a utilização das TICs fora de fins puramente comerciais e de vigilância, que evidenciam a apropriação coletiva dos meios tecnológicos 
para emprego alternativo no ambiente urbano por aqueles que habitam a cidade. Assim, que no discurso a solução de aplicação das TICs no tecido urbano para evitar problemas não seja um recurso argumentativo para instalar mecanismos de controle e privatização dos espaços públicos.

Sem intenção de propor uma reorganização social, que já está instituída em redes, o que se reforça é a indispensável transparência quanto ao que se fará com os dados coletados, devendo ser reivindicada a consciência disso pela sociedade civil, pois a não exigência de pagamento por um produto ou serviço, depreende-se, bem provavelmente, que se seja o próprio produto, sempre há um custo implícito.

A partir das reflexões produzidas ao longo da pesquisa, define-se a dimensão Segurança de Dados como o empenho de tratar o regime invisivel da vigilância, por buscar entender as origens da vigilância contemporânea e quais as relações com os poderes instituídos. Observar as questões complexas próprias de estrutura e agenciamento, bem como as funções desempenhadas pelas TICs, suas consequências nos grupos sociais, nos indivíduos e como artifícios de resistência.

\section{CONSIDERAÇÕES FINAIS}

A proposta deste artigo foi discorrer sobre a Segurança de Dados como uma dimensão específica a ser pensada na aplicação e uso das TICs no ambiente urbano. Para isso, depreende-se que Cidade Inteligente não se trata apenas de combinar ambiente digital e comunidade real, mas de promover um elevado nível de conhecimento, além de ser capaz de gerir e fomentar o compartilhamento deste conhecimento, assim como não se restringe a uma alternativa de ação de grupos específicos ligados às atividades de inovação, mas sim de compor uma interação entre os cidadãos, para que a tomada de decisões venha a ser aberta à construção coletiva. Outro ponto é que, à Cidade Inteligente não compete apenas a existência de plataformas web para disponibilizar informações e serviços, mas estes estarem centrados nos cidadãos, no sentido de pensar e planejar a utilização da informação existente de forma vantajosa, bem como fornecer segurança quanto aos dados e seu armazenamento, além de dispor de transparência em tempo real das atividades e serviços econômicos e sociais, à disposição de todos. Pelo já exposto, em um exercício de estabelecer uma noção, entende-se que a Cidade Inteligente lida com pessoas, TICs, concatenação da inteligência existente (humana e coletiva junto com a artificial promovida pela técnica), para aplicação na urbe.

Dessa forma, é preciso ter ciência que os dados produzidos pelos cidadãos são valiosos e existe o comércio deles para fins diversos e ainda obscuros, sem transparência a quem os produz. Propor uma inteligência para a cidade requer também ter controle e entendimento dessa situação, por meio de um tratamento específico de Segurança de Dados e poder resguardar àquelas que alimentam as informações para uma cidade mais inteligente. Como já mencionado, outras dimensões foram pensadas como Cultura, 
Gestão de risco e resiliência, Mobilidade urbana, Gestão otimizada de recursos disponíveis e Comunicação, salienta-se que mais poderão ser cogitadas, pois cada cidade possui suas particularidades.

\section{REFERÊNCIAS}

CADWALLADR, C.; GRAHAM-HARRISON, E. The Guardian. Cambridge Analytica execs boast of role in getting Donald Trump elected. Publicado em 21 mar 2018 às 11h45. Disponivel em: <https://www. theguardian.com/uk-news/2018/mar/20/cambridge-analytica-execs-boast-of-role-in-getting-trumpelected>. Acesso em: 2 ago. 2018.

CGI. Pesquisa sobre o uso das Tecnologias de Informação e Comunicação nos domicílios brasileiros TIC Domicílios 2016. Disponível em: <https://cgi.br/media/docs/publicacoes/2/TIC_DOM_2016_LivroEletronico.pdf>. Acesso em: 27 mai. 2018.

FANAYA, P. F. Cidades inteligentes como ambientes cognitivos. In: SANTAELLA, L. (Org.). Cidades inteligentes: por que, para quem? São Paulo: Estação das Letras e Cores, 2016. p. 12-23

FLORES, P. Nexo Jornal. O que a Cambridge Analytica, que ajudou a eleger Trump, quer fazer no Brasil. Publicação em 08 dez 2017, atualizado 09 dez às 11h35. Disponivel em: <https://www.nexojornal.com. br/expresso/2017/12/08/0-que-a-Cambridge-Analytica-que-ajudou-a-eleger-Trump-quer-fazer-noBrasil> Acesso em: 2 ago. 2018.

GIL, A. C. Como elaborar projetos de pesquisa. São Paulo: Atlas, 2006. 176 p.

INTERNETLAB. Quem defende seus dados?. 2018. Disponivel em: <http://quemdefendeseusdados.org. br/pt/>. Acesso em: 2 ago. 2018.

KOMNINOS, N. The architecture of intelligent cities. Intelligent Environments, v. 6, p. 13-20, 2006. Disponivel: <http://www.urenio.org/wp-content/uploads/2008/11/2006-The-Architecture-of-Intel-Cities-IE06.pdf> Acesso em: 14 jul. 2018.

KOMNINOS, N.; SEFERTZI, E. Intelligent Cities: R\&D off shoring, web 2.0 product development and globalization of innovation systems. In: KNOWLEDGE CITIES SUMMIT, $2^{\circ}, 2009$, Shenzhen. Anais... Thessaloniki: URENIO Research Unit, 2009. p. 1-8. Disponível: <http://www.urenio.org/wp-content/uploads/2008/11/Intelligent-Cities-Shenzhen-2009-Komninos-Sefertzi.pdf> Acesso em: 28 abr. 2018.

LEMOS, A. Coisas. In Correio do Povo. Caderno de Sábado, Porto Alegre, 26 de março de 2013. Disponível em: <http://rae.fgv.br/sites/rae.fgv.br/files/artigos/gv_v12n2_46-49.pdf> Acesso em: 29 abr. 2018. 
LEMOS, A.; MONT'ALVERNE, A. Smart Cities in Brazil. Experiences underway in Búzios, Porto Alegre and Rio de Janeiro. Revista Comunicação Midiática, Bauru, v. 10, n. 3, p. 21-39, dez. 2015.

MEIRELES, G. P. A comunicação e o urbano criativo e inteligente: contribuição conceitual aplicada às cidades de pequeno e médio porte. 2018. 180 f. Dissertação (Mestrado em Comunicação e Indústria Criativa) - Universidade Federal do Pampa, São Borja, Rio Grande do Sul.

SANTAELLA, L. (Org.). Cidades inteligentes: por que, para quem? 1. ed. São Paulo: Estação das Letras e Cores, 2016. 240 p.

SANTAELLA, L. Comunicação ubíqua: repercussões na cultura e na educação. São Paulo: Paulus, 2013. $376 \mathrm{p}$.

SANTAELLA, L. Mobile and Locative Media: In Between Thánatos and Eros. In: FIRMINO, R. J. (Ed.). ICTs for Mobile and Ubiquitous Urban Infrastructures: Surveillance, Locative Media and Global Networks. Hershey: IGI Global, 2011. p. 294-311.

SÃo BORJA CONECTADA. Produção de Greice Meireles. Roteiro: Greice Meireles. São Borja: Programa de Pós-Graduação em Comunicação e Indústria Criativa, 2017. (7 websódios), son., color. Youtube. Disponivel em: <https://www.youtube.com/watch?v=fLWeUSFAlzs\&list=PLOv55X2uwrll512U0ooD-XyiK3KEQQX12>.

SELADA, C. (Orgs). İndice de Cidades Inteligentes - Portugal. ed 1. INTELI - Inteligência em Inovação. Lisboa: Europress, 2012. 117 p.

STUMPF, I. R. C. Pesquisa bibliográfica. In: DUARTE, J. (Orgs). Métodos e técnicas de pesquisa em comunicação. 2.ed. São Paulo: Atlas, 2010. p. 51-61.

TOWNSEND, A. M. Smarts Cities: Big data, civic hackers, and the quest for a new utopia. New York: W. W. Norton \& Company, 2013. 400 p. 